ARTICLE

Received 5 Mar 2015 | Accepted 11 Aug 2015 | Published 11 Sep 2015

DOI: $10.1038 /$ ncomms 9340

OPEN

\title{
Monolayered $\mathrm{Bi}_{2} \mathrm{WO}_{6}$ nanosheets mimicking heterojunction interface with open surfaces for photocatalysis
}

Yangen Zhou', Yongfan Zhang ${ }^{2,3}$, Mousheng Lin' ${ }^{1}$ Jinlin Long ${ }^{1}$, Zizhong Zhang ${ }^{1}$, Huaxiang Lin ${ }^{1}$ Jeffrey C.-S. Wu ${ }^{4} \&$ Xuxu Wang ${ }^{1}$

Two-dimensional-layered heterojunctions have attracted extensive interest recently due to their exciting behaviours in electronic/optoelectronic devices as well as solar energy conversion systems. However, layered heterojunction materials, especially those made by stacking different monolayers together by strong chemical bonds rather than by weak van der Waal interactions, are still challenging to fabricate. Here the monolayer $\mathrm{Bi}_{2} \mathrm{WO}_{6}$ with a sandwich substructure of $[\mathrm{BiO}]^{+}-\left[\mathrm{WO}_{4}\right]^{2-}-[\mathrm{BiO}]^{+}$is reported. This material may be characterized as a layered heterojunction with different monolayer oxides held together by chemical bonds. Coordinatively unsaturated $\mathrm{Bi}$ atoms are present as active sites on the surface. On irradiation, holes are generated directly on the active surface layer and electrons in the middle layer, which leads to the outstanding performances of the monolayer material in solar energy conversion. Our work provides a general bottom-up route for designing and preparing novel monolayer materials with ultrafast charge separation and active surface.

\footnotetext{
${ }^{1}$ State Key Laboratory of Photocatalysis on Energy and Environment, Fuzhou University, Fuzhou 350002, China. ${ }^{2}$ Department of Chemistry, Fuzhou University, Fuzhou 350108, China. ${ }^{3}$ Fujian Provincial Key Laboratory of Theoretical and Computational Chemistry, Xiamen 361005, China.

${ }^{4}$ Department of Chemical Engineering, National Taiwan University, Taipei 10617, Taiwan. Correspondence and requests for materials should be addressed to X.W. (email: xwang@fzu.edu.cn).
} 
S emiconductor-based heterojunctions are able to facilitate fast charge separation, and thus have emerged as one of important strategies for creation of efficient solar energy conversion systems ${ }^{1-4}$. It is well known that a heterojunction in nature is the interface that occurs between two dissimilar crystalline semiconductors. The heterojunction effect on charge separation are thought to come from the built-in electric field forming at the atomically thin interface ${ }^{1}$. Compared with conventional powder heterojunction materials, the layered heterojunctions composed of different ultrathin twodimensional (2D) materials have sparked widespread interests because of the well-defined heterostructures almost as thin as the interface of conventional heterojunctions. As great successes on monolayer materials have been achieved ${ }^{5-7}$, the stacks of different monolayers held together by van der Waals forces have been realized $^{8-15}$. However, the layered heterojunctions composed of different monolayers stacked together by strong chemical bonds have been rarely studied. Since chemical bonding between monolayers can greatly enhance charge separation and even induce new energy band structures, the layered heterojunctions are considerably appealing ${ }^{16,17}$. Besides charge separation, exposure of active sites (mainly unsaturated atoms) is also key to affect the material performances in solar energy conversion ${ }^{18,19}$. The monolayers from van der Waals layered materials (with layers stacked by van der Waals forces) such as $\mathrm{MoS}_{2}$ have been found active sites only at the edge ${ }^{20-22}$. Postprocessing methods such as defect engineering have often been applied for creating more active sites on these $2 \mathrm{D}$ materials ${ }^{23-25}$. Aurivillius phase oxides, as complex layered materials, consist of alternate stacking of $\left[\mathrm{Bi}_{2} \mathrm{O}_{2}\right]$ layers and perovskite-type layers with oxygen atoms shared between layers. This means that such a monolayer material maybe regarded as the stacks of different monolayer oxides by chemical bonds, and may possess oxygendepleted surfaces that expose a huge number of active sites.

It is well known that monolayer materials maybe achieved on a small scale by mechanical exfoliation or chemical vapour

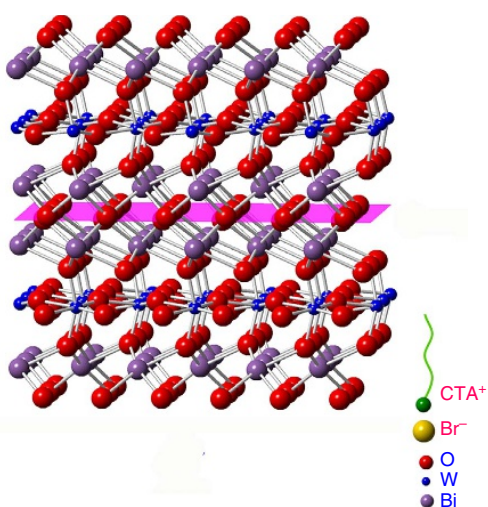

b

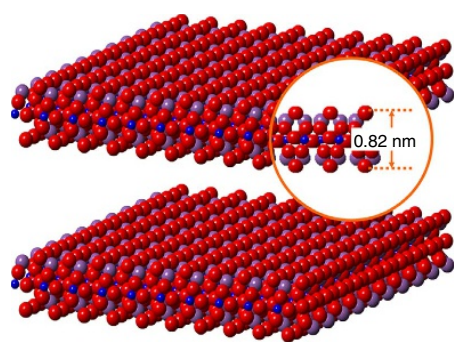

C

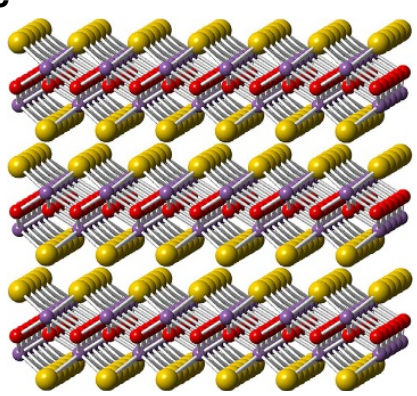

d

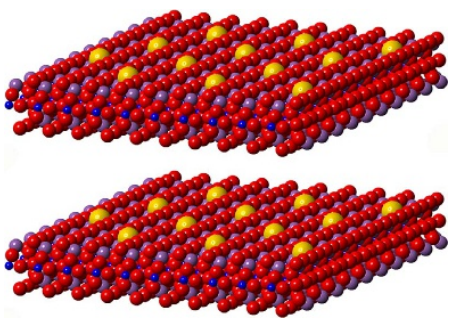

| I

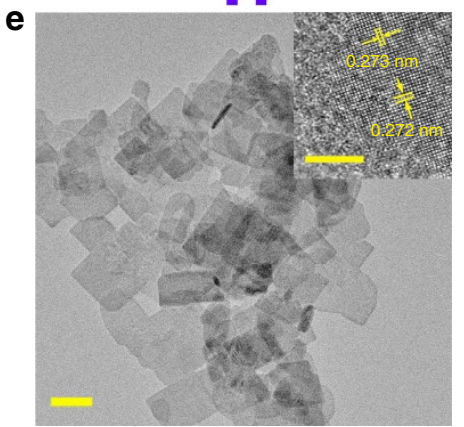

$\mathbf{f}$

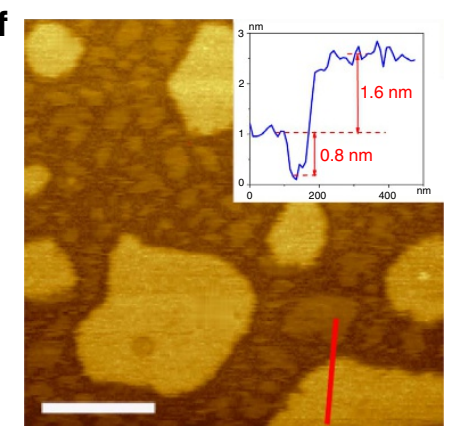

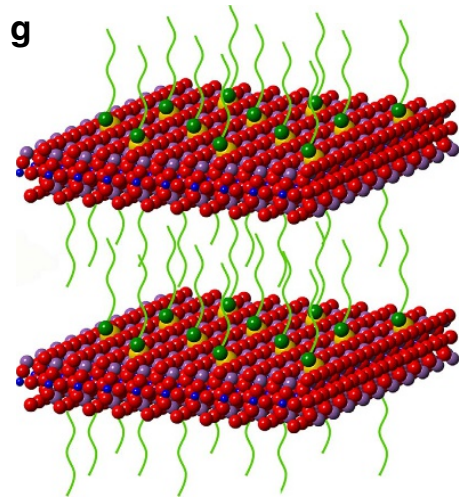

| I

h

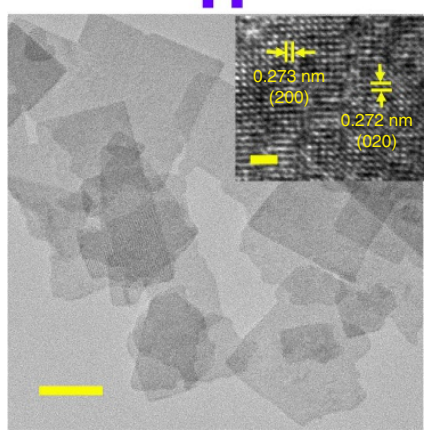

i

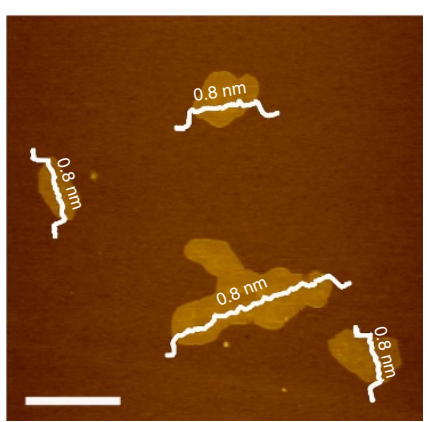

Figure 1 | Synthesis of monolayer $\mathbf{B i}_{\mathbf{2}} \mathbf{W O}_{6}$. (a) Crystal structure of $\mathrm{Bi}_{2} \mathrm{WO}_{6}$. (b) Structure of pristine monolayer $\mathrm{Bi}_{2} \mathrm{WO}_{6}$. (c) Crystal structure of $\mathrm{BiOBr}$. (d) Formation mechanism of the monolayer $\mathrm{Bi}_{2} \mathrm{WO}_{6}$ with $\mathrm{Br}^{-}$ions assistance. (e) TEM image of the synthesized $\mathrm{Bi}_{2} \mathrm{WO}_{6}$ with $\mathrm{Br}^{-}$ions assistance; inset is the corresponding HRTEM image. (f) AFM image of the monolayer $\mathrm{Bi}_{2} \mathrm{WO}_{6}$ prepared by $\mathrm{Br}^{-}$ions assistance; inset is the corresponding height profile on the red line. (g) Formation mechanism of the monolayer $\mathrm{Bi}_{2} \mathrm{WO}_{6}$ with CTAB assistance. (h) TEM image and the corresponding HRTEM image of the $\mathrm{Bi}_{2} \mathrm{WO}_{6}$ prepared with $\mathrm{CTAB}$ assistance. (i) AFM image of the monolayer $\mathrm{Bi}_{2} \mathrm{WO}_{6}$ prepared by CTAB assistance. Scale bar, $500 \mathrm{~nm}(\mathbf{f}, \mathbf{i}), 50 \mathrm{~nm}(\mathbf{e}, \mathbf{h})$, $5 \mathrm{~nm}$ (insets in $\mathbf{e}$ ) and $1 \mathrm{~nm}$ (insets in $\mathbf{h}$ ). 
deposition $^{26-28}$. However, the practical and large-scale synthesis of freestanding monolayers in liquid phase is irreplaceable for many applications. Up to now, most monolayer materials are produced by liquid exfoliation of the van der Waals layered materials, such as graphene, boron nitride $(\mathrm{BN})$ and transition metal dichalcogenides ${ }^{29-31}$. However, it is difficult to exfoliate the layered materials with layers stacked by strong chemical bonds. The alternative method, a bottom-up approach, has been used to produce multilayer nanosheets, but rarely succeed in monolayer materials ${ }^{32,33}$. The key to preparation of such monolayers by the bottom-up route is to keep monolayers from stacking together.

We develop a cetyltrimethylammonium bromide (CTAB)assisted bottom-up route to fabricate such freestanding monolayer materials. The successfully synthesized monolayer Aurivillius oxide $\mathrm{Bi}_{2} \mathrm{WO}_{6}$ has a sandwich substructure of $[\mathrm{BiO}]^{+}$ $\left[\mathrm{WO}_{4}\right]^{2-}{ }_{-}[\mathrm{BiO}]^{+}$, mimicking heterojunction interface with space charge. The $\mathrm{Br}^{-}$ions from $\mathrm{CTAB}$ strongly adsorb on the monolayers surfaces and thus make the monolayers negatively charged. In the self-assembly process, stacking of the monolayers is blocked by Coulomb repulsion forces and the hydrophobic chains of $\mathrm{CTA}^{+}$ions. The $\mathrm{Br}^{-}$ions on surface induce a decrease in the bandgap energy of the monolayers. The surface $\mathrm{Bi}$ atoms are coordinatively unsaturated and thus the monolayers surfaces expose a huge number of active sites. On irradiation, holes are directly generated on the active surfaces and electrons in the middle layer, leading to ultrafast charge separation. Both the highly active surface and the ultrafast charge separation contribute to the superior photocatalytic performances of the monolayer material. In the presence of positive dyes, the visible light activity of the monolayers can be greatly enhanced due to photosensitization of the strongly adsorbed dye.

\section{Results}

Self-assembly of $\mathbf{B i}_{2} \mathbf{W O}_{6}$ monolayers. As shown in Fig. 1a, $\mathrm{Bi}_{2} \mathrm{WO}_{6}$ is a layered material built up of $\left[\mathrm{Bi}_{2} \mathrm{O}_{2}\right]$ layers and corner-shared $\mathrm{WO}_{6}$ octahedral layers. Monolayer $\mathrm{Bi}_{2} \mathrm{WO}_{6}$ has two possible configurations: $[\mathrm{BiO}]^{+}{ }_{-}\left[\mathrm{WO}_{4}\right]^{2-}{ }_{-}[\mathrm{BiO}]^{+}$(sandwich substructure) and $\left[\mathrm{Bi}_{2} \mathrm{O}_{2}\right]^{2+}-\left[\mathrm{WO}_{4}\right]^{2-}$ (non-sandwich substructure). Density functional theory (DFT) calculations show that the surface energy of the sandwich configuration is $0.86 \mathrm{~J} \mathrm{~m}^{-2}$, notably smaller than that of the non-sandwich substructure $\left(2.27 \mathrm{~J} \mathrm{~m}^{-2}\right)$. It can be deduced accordingly that the monolayer $\mathrm{Bi}_{2} \mathrm{WO}_{6}$ has the sandwich structure, as presented in Fig. 1b.

As mentioned above, the monolayer $\mathrm{Bi}_{2} \mathrm{WO}_{6}$ exposes coordinatively unsaturated $\mathrm{Bi}$ atoms on surface (Fig. 1b). This induces strong interaction between the monolayers and therefore makes the monolayers to stack easily into multilayers. So far no monolayer nanosheets have been achieved through bottom-up route $^{33,34}$. Obviously, weakening the interaction between the monolayers is a key to successfully obtain the monolayer material. It is well known that $\mathrm{BiOBr}$ is a typical layered material consisting of $(\mathrm{Br}-\mathrm{Bi}-\mathrm{O}-\mathrm{Bi}-\mathrm{Br})$ slices stacked together by van der Waal interaction, in which the $\mathrm{Br}$ atoms terminate the dangling bonds of slices (Fig. 1c) ${ }^{35}$. When $\mathrm{Br}^{-}$ions were introduced in the bottom-up synthesis system for $\mathrm{Bi}_{2} \mathrm{WO}_{6}$, they would bond to the monolayers surfaces to terminate the dangling bonds partly and make the surface negatively charged, which would suppress the stacking of the monolayers, as shown in Fig. 1d.

As expected, the monolayer $\mathrm{Bi}_{2} \mathrm{WO}_{6}$ was achieved when $\mathrm{KBr}$ as a $\mathrm{Br}^{-}$source was added to the hydrothermal reaction system of $\mathrm{Bi}\left(\mathrm{NO}_{3}\right)_{3} \cdot 5 \mathrm{H}_{2} \mathrm{O}$ and $\mathrm{Na}_{2} \mathrm{WO}_{4} \cdot 2 \mathrm{H}_{2} \mathrm{O}(\mathrm{Br} / \mathrm{Bi}$ atomic ratio is 1:20). The $\mathrm{X}$-ray diffraction patterns of the resulted sample are shown in Supplementary Fig. 1. All the diffraction peaks can be indexed to an orthorhombic $\mathrm{Bi}_{2} \mathrm{WO}_{6}$ phase with lattice parameters $a=5.457 \AA, b=5.436 \AA$ and $c=16.427 \AA$ (JCPDS No. 73-2020). The transmission electron microscopy (TEM) image in Fig. 1e exhibits the synthesized $\mathrm{Bi}_{2} \mathrm{WO}_{6}$ with a sheetshaped structure. Inset in Fig. 1e gives the corresponding highresolution transmission electron microscopy (HRTEM) image. The marked interplanar spacings of (200) and (020) planes indicate that the $\mathrm{Bi}_{2} \mathrm{WO}_{6}$ nanosheets expose $\{001\}$ facets. The atomic force microscopic (AFM) image and the corresponding height histograms of the nanosheets are presented in Fig. If and Supplementary Fig. 2, respectively. It can be seen that the thinnest nanosheets have a thickness of ca. $0.8 \mathrm{~nm}$, which agrees well with that of monolayer $\mathrm{Bi}_{2} \mathrm{WO}_{6}$ sheet along [001] direction (corresponding to $1 / 2$ of the unit cell size in $c$-axis direction). This shows that the $\mathrm{Bi}_{2} \mathrm{WO}_{6}$ monolayers can be achieved by a $\mathrm{Br}$ ions-assisted hydrothermal method. Unfortunately, some bilayer nanosheets are observed in the products.

$\mathrm{CTAB}$ is a long-chain cationic surfactant containing $\mathrm{Br}^{-}$ions. When $\mathrm{CTAB}$ instead of $\mathrm{KBr}$ was used in the synthesis, the CTA ${ }^{+}$ ions would adsorb on the surface with bonding of $\mathrm{Br}^{-}$ions to the monolayers surfaces. Thus, the extra surface repulsion from the hydrophobic chains of $\mathrm{CTA}^{+}$further prevents stacking of the monolayers, as showed in Fig. 1g. In this case, the high-quality monolayer $\mathrm{Bi}_{2} \mathrm{WO}_{6}$ was successfully prepared. The X-ray diffraction result reveals that the obtained sample is pure phase $\mathrm{Bi}_{2} \mathrm{WO}_{6}$ (Supplementary Fig. 1). The sample shows weaker X-ray diffraction peaks than that prepared with only $\mathrm{Br}^{-}$ions, indicating the smaller size of the sample. The TEM image (Fig. 1h) displays sheet-shaped structures of the sample. It can be seen from the HRTEM image (inset of Fig. 1h) that marked interplanar spacings of (200) and (020) planes appear on the sample, indicating the $\{001\}$ exposed facets of the nanosheets. The AFM image in Fig. 1i shows that the thickness of nanosheets is very close to that of monolayer $\mathrm{Bi}_{2} \mathrm{WO}_{6}$ slab (the height histograms in Supplementary Fig. 3). These results illustrate that the well-defined $\mathrm{Bi}_{2} \mathrm{WO}_{6}$ monolayers were successfully prepared by the one-pot CTAB-assisted hydrothermal process.

In addition, a control synthesis with neither $\mathrm{KBr}$ nor $\mathrm{CTAB}$ assistance was also performed for comparison. Only the $\mathrm{Bi}_{2} \mathrm{WO}_{6}$ nanocrystals were obtained in this case. Both the TEM image (Supplementary Fig. 4) and the HRTEM image (Supplementary Fig. 5) show that the sample is $20 \mathrm{~nm}$ diameter near-spherical aggregation consisting of $8 \mathrm{~nm}$ diameter nanocrystals. The X-ray diffraction pattern of nanocrystals is the same as that of the monolayers obtained by CTAB assistance (Supplementary Fig. 6), indicating the same crystal phase. Above results show that the $\mathrm{Br}^{-}$and $\mathrm{CTA}^{+}$are responsible for the formation of monolayer $\mathrm{Bi}_{2} \mathrm{WO}_{6}$, which were further discussed in Supplementary Figs 7-9.

Chemical compositions of $\mathrm{Bi}_{2} \mathrm{WO}_{6}$ monolayers. X-ray photoelectron spectroscopic (XPS) characterizations were conducted to reveal the chemical compositions of the monolayer $\mathrm{Bi}_{2} \mathrm{WO}_{6}$ (ref. 36). The $\mathrm{Br} 3 d, \mathrm{Bi} 4 f, \mathrm{~W} 4 f$ and $\mathrm{O} 1 s$ XPS spectra of the $\mathrm{Bi}_{2} \mathrm{WO}_{6}$ monolayers and nanocrystals are shown in the Fig. 2. For the monolayers, a strong $\mathrm{Br} 3 d$ peak is observed at the binding energy of $68.5 \mathrm{eV}$, which suggests that the $\mathrm{Br}^{-}$ions from CTAB are bonded to the surface $\mathrm{Bi}$ atoms of the monolayer ${ }^{37}$. Compared with the nanocrystals, the monolayers present two asymmetric $\mathrm{Bi}$ $4 f$ peaks (Fig. 2b), indicating the different chemical states of Bi for the two samples. Both the asymmetric $\mathrm{Bi} 4 f$ peaks can be deconvolved into two peaks. The shoulder peaks $(165.0 \mathrm{eV}$ for $\mathrm{Bi}$ $4 f_{5 / 2}$, and $159.9 \mathrm{eV}$ for and $\mathrm{Bi} 4 f_{7 / 2}$ ) occur at higher binding energies, indicating higher electropositive $\mathrm{Bi}$ appearing in the monolayers. This can be indicative of some $\mathrm{Bi}$ atoms bonded with 

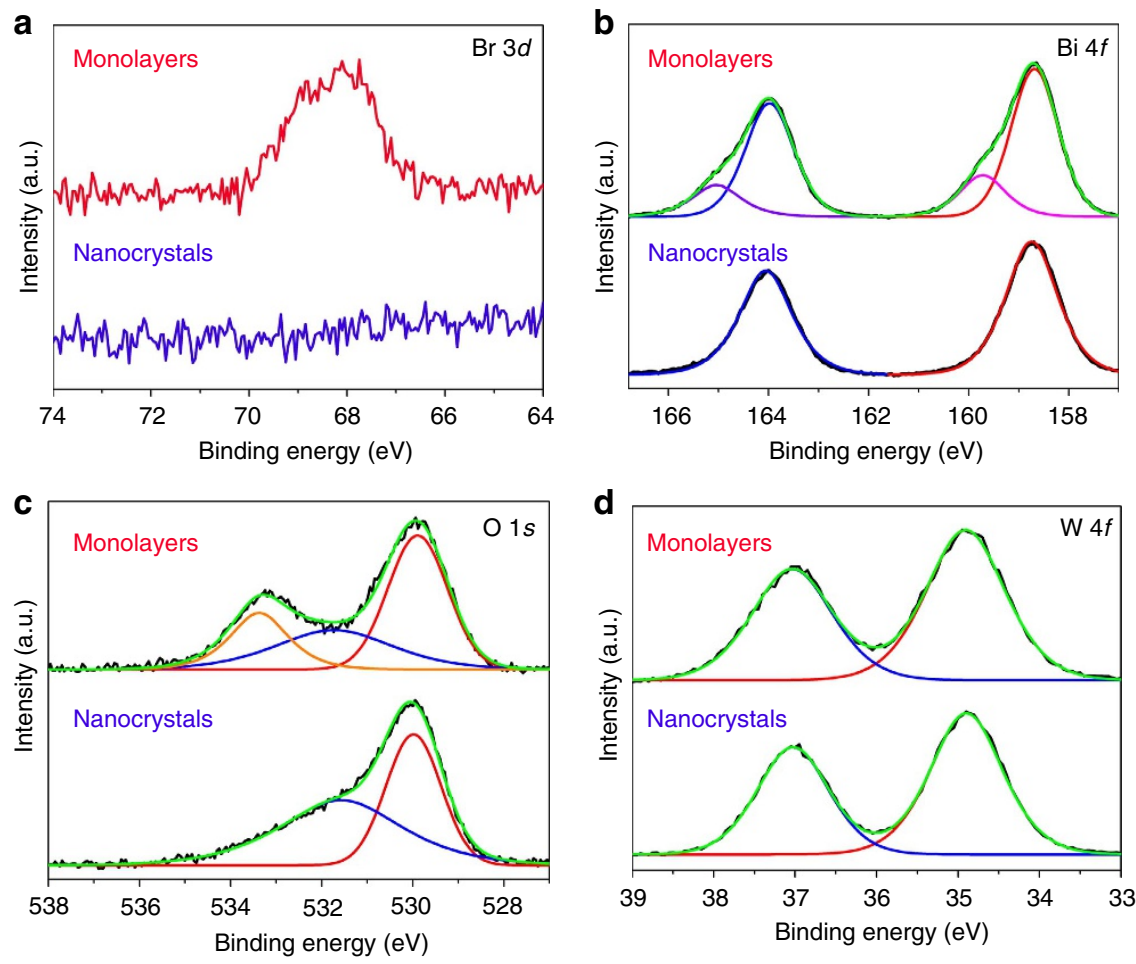

Figure 2 | XPS of $\mathbf{B i}_{2} \mathbf{W O}_{\mathbf{6}}$ samples. (a) $\mathrm{Br} 3 d_{1}$ (b) $\mathrm{Bi} 4 f$, (c) $\mathrm{O}$ 1s and (d) $\mathrm{W} 4 f$.

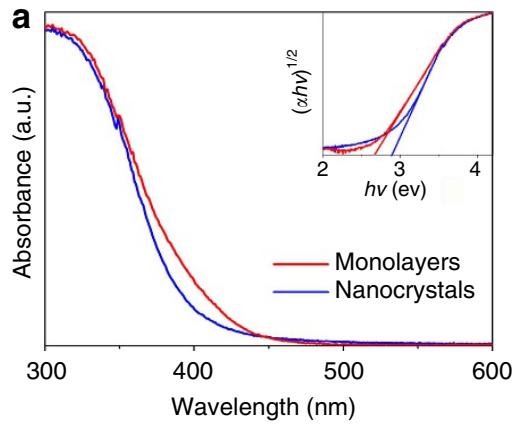

C
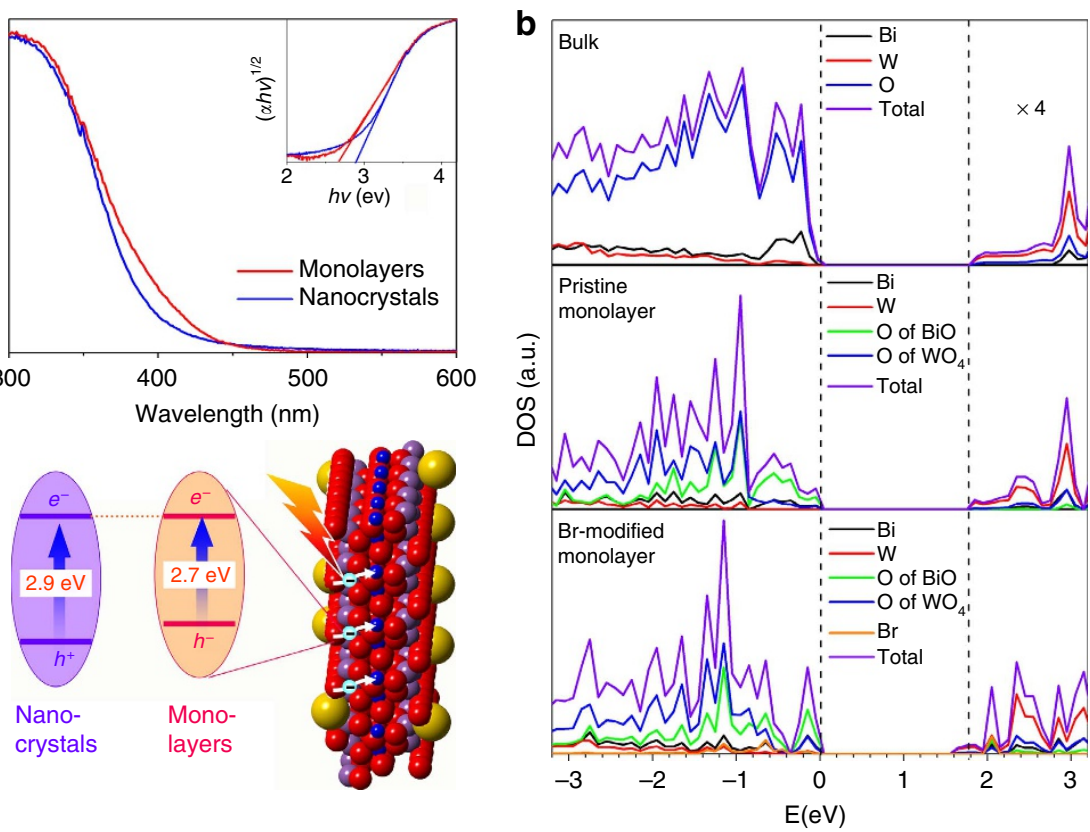

Figure 3 | Bandgap states of $\mathbf{B i}_{\mathbf{2}} \mathbf{W} \mathbf{O}_{\mathbf{6}}$ samples. (a) Diffuse reflectance ultraviolet-visible spectra of $\mathrm{Bi}_{2} \mathrm{WO}_{6}$ samples. (b) Calculated density of states (DOSs) of $\mathrm{Bi}_{2} \mathrm{WO}_{6}$ bulk, pristine monolayer and $\mathrm{Br}$-modified monolayer. The Fermi level is taken as the energy zero. (c) Band energy diagrams of $\mathrm{Bi}_{2} \mathrm{WO}_{6}$ nanocrystals and monolayers. $\mathrm{W}, \mathrm{O}, \mathrm{Bi}$ and $\mathrm{Br}$ atoms are represented as blue, red, purple and yarrow spheres, respectively.

the surface $\mathrm{Br}$ atoms ${ }^{37}$. Figure $2 \mathrm{c}$ is $\mathrm{O} 1 \mathrm{~s}$ spectra, two peaks at $529.9 \mathrm{eV}$ and $531.7 \mathrm{eV}$ are observed for both samples, which are assigned respectively to lattice oxygen and bridging hydroxyls ${ }^{38}$. But the peak at $533.3 \mathrm{eV}$ belonging to physisorbed water only appears for the monolayers ${ }^{39}$. This is because the open metal sites on the monolayers surfaces have strong interaction with surrounding water. Figure $2 \mathrm{~d}$ shows that the W $4 f$ spectra are almost comparable for two samples, which can be explained by
$\left[\mathrm{WO}_{4}\right]^{2-}$ locating at the middle layers of the monolayers and hardly affected by the surface $\mathrm{Br}$ atoms.

Quantitative XPS analysis shows that the ratios $\mathrm{Br} / \mathrm{Bi} / \mathrm{W}$ are $0.2 / 2.1 / 1.0$ in the monolayer $\mathrm{Bi}_{2} \mathrm{WO}_{6}$ sample, of which the $\mathrm{Bi} / \mathrm{W}$ ratio is almost identical to that of the nanocrystals. This result implies that the $\mathrm{Br}^{-}$ions are non-stoichiometrically coordinated to $[\mathrm{BiO}]^{+}$layers together with the $\mathrm{CTA}^{+}$. An additional experiment shows that the $\mathrm{CTA}^{+}$ions on the monolayers 
a

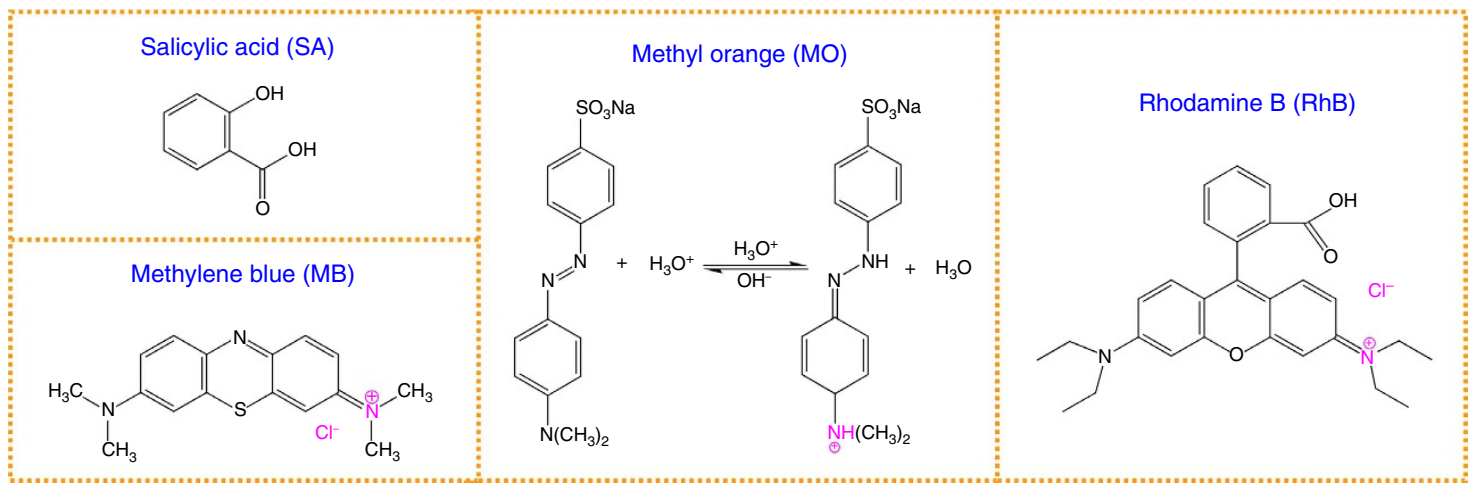

b

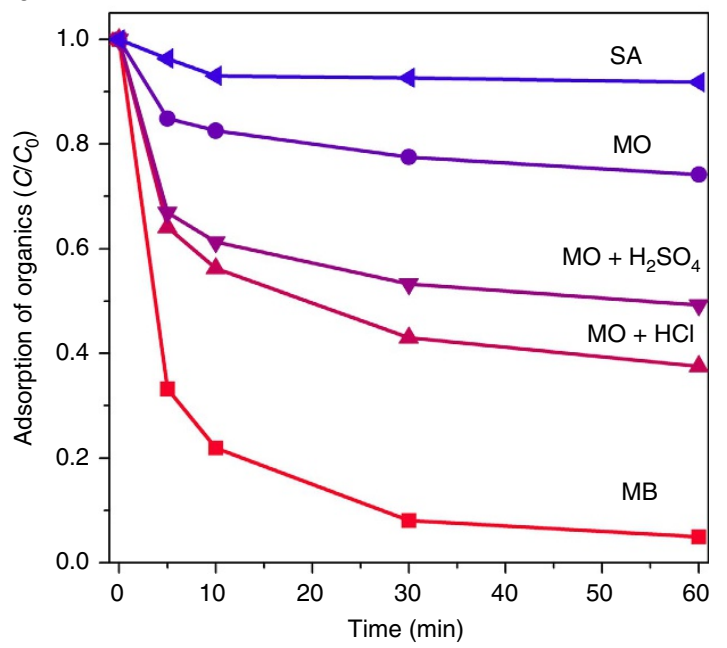

C
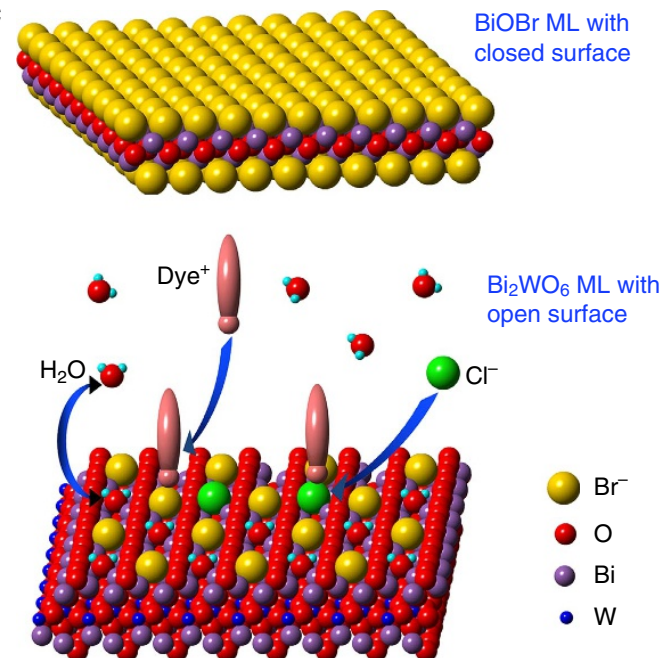

Figure 4 | Open surface of the $\mathbf{B i}_{\mathbf{2}} \mathbf{W} \mathbf{O}_{\mathbf{6}}$ monolayers. (a) Molecular structures of various organic contaminants. (b) Adsorption of various organic pollutants over the $\mathrm{Bi}_{2} \mathrm{WO}_{6}$ monolayers. (c) Schematic diagram showing the interactions between the open surface of monolayer $\mathrm{Bi}_{2} \mathrm{WO}_{6}$ and surrounding species.

surfaces can be removed by washing (Supplementary Fig. 10). $\mathrm{H}^{+}$ions maybe substitute the CTA ${ }^{+}$ions for keeping charge balance of the monolayer in the washing process. The residual amount of $\mathrm{CTA}^{+}$ions on the surface are very low and no obvious influence was observed on the photocatalytic activity of the monolayers (Supplementary Figs 11-12).

Synthesis of other monolayer materials. To verify the universal applicability of this self-assembly route, preparation of monolayer $\mathrm{Bi}_{2} \mathrm{O}_{2} \mathrm{CO}_{3}$ was studied also in the same conditions. The result shows that the monolayer $\mathrm{Bi}_{2} \mathrm{O}_{2} \mathrm{CO}_{3}$ with a thickness of $0.55 \mathrm{~nm}$ was successfully obtained in the presence of $\mathrm{CTAB}$, as showed in the Supplementary Figs $13-15$. Besides $\mathrm{Bi}_{2} \mathrm{WO}_{6}$ and $\mathrm{Bi}_{2} \mathrm{O}_{2} \mathrm{CO}_{3}$, the Aurivillius phase layered oxides (general formula $\mathrm{Bi}_{2} \mathrm{~A}_{n-1} \mathrm{~B}_{n} \mathrm{O}_{3 n+3}$; $\mathrm{A}=\mathrm{Ca}, \mathrm{Sr}, \mathrm{Ba}, \mathrm{Pb}, \mathrm{Bi}, \mathrm{Na}, \mathrm{K}$ and $\mathrm{B}=\mathrm{Ti}, \mathrm{Nb}, \mathrm{Ta}, \mathrm{Mo}, \mathrm{W}, \mathrm{Fe})$, an important class of functional materials including photocatalysts, superconductors, and ferroelectric materials ${ }^{40-42}$, have the common feature of containing $\left[\mathrm{Bi}_{2} \mathrm{O}_{2}\right]$ layers in crystal structure. Thus, a huge number of monolayer Aurivillius materials can be formed by the similar mechanism of self-assembly.

Band gap of the monolayer $\mathbf{B i}_{2} \mathbf{W O}_{6}$. Figure $3 \mathrm{a}$ shows ultraviolet-visible diffuse reflectance spectrum of the $\mathrm{Bi}_{2} \mathrm{WO}_{6}$ samples. The bandgap energies of the samples were estimated from the plots of $(\alpha h v)^{1 / 2}$ versus the energy of absorbed light (inset of Fig. 3a $)^{43}$. The bandgap energy of the monolayers is ca. $2.7 \mathrm{eV}$, lower than that of the nanocrystals by $0.2 \mathrm{eV}$. To understand the differences, band structures of the bulk (multilayers), pure monolayer (unmodified) and Br-modified monolayer of $\mathrm{Bi}_{2} \mathrm{WO}_{6}$ were investigated theoretically (Supplementary Fig. 16). The corresponding densities of states are presented in Fig. 3b. Although the bandgaps from DFT calculations are usually smaller than that from the experimental determination, the DFT calculations often provide important insights into the physicochemical properties of the materials ${ }^{43,44}$. For the unmodified monolayers and the bulk, the top of valence band and the bottom of conduction band are mainly originated from hybrid $\mathrm{Bi} 6 s-\mathrm{O} 2 p$ orbital and $\mathrm{W} 5 d$ orbital, respectively (Fig. 3b). However for the Br-modified monolayers, the bottom of conduction band is still originated from W $5 d$ orbital, but the top of valence band is composed of the hybridized orbital of $\mathrm{Bi} 6 s$, O $2 p$ and $\mathrm{Br} 4 p$ (Fig. 3b). Due to more negative potential of their top of valence, the $\mathrm{Br}$-modified monolayers show a narrower bandgap than the unmodified monolayers and the nanocrystals.

The sandwich substructure of $[\mathrm{BiO}]^{+}-\left[\mathrm{WO}_{4}\right]^{2-}-[\mathrm{BiO}]^{+}$of monolayer $\mathrm{Bi}_{2} \mathrm{WO}_{6}$ simulates the heterojunction interface with space charge that promotes separation of the photogenerated carriers in the interface, as shown in Fig. 3c. It should be noted that the bottom of conduction band is originated from $\mathrm{W} 5 d$ orbital located in the middle layer, and the top of valence band is mainly composed of $\mathrm{O} 2 p$ orbital from the surface $[\mathrm{BiO}]^{+}$layers (Fig. 3b). On irradiation, holes and electrons can be generated, respectively, on the surface layer and in the middle layer and thus are separated directly. In brief, for the monolayer $\mathrm{Bi}_{2} \mathrm{WO}_{6}$, the 
a
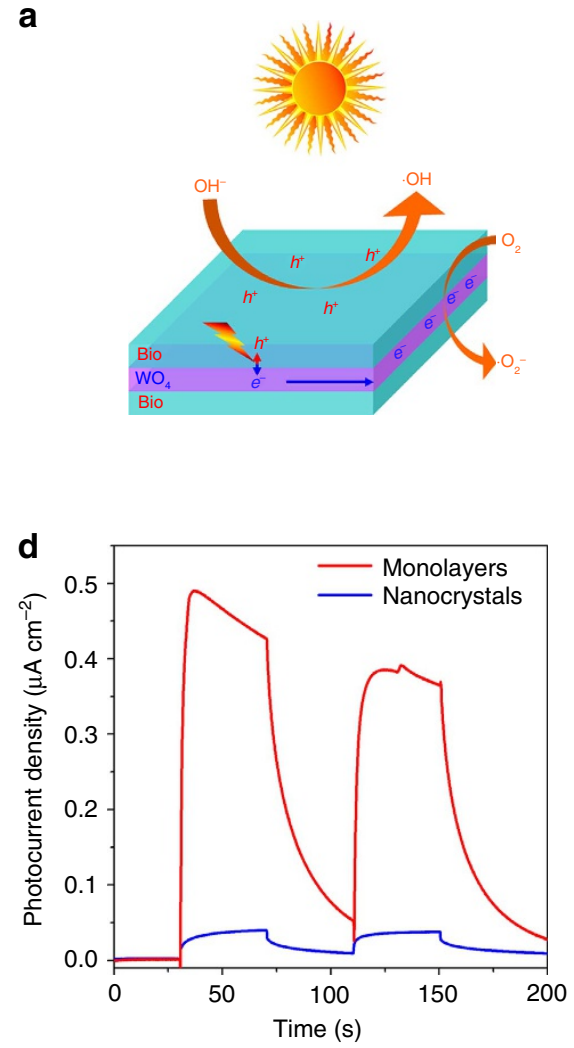
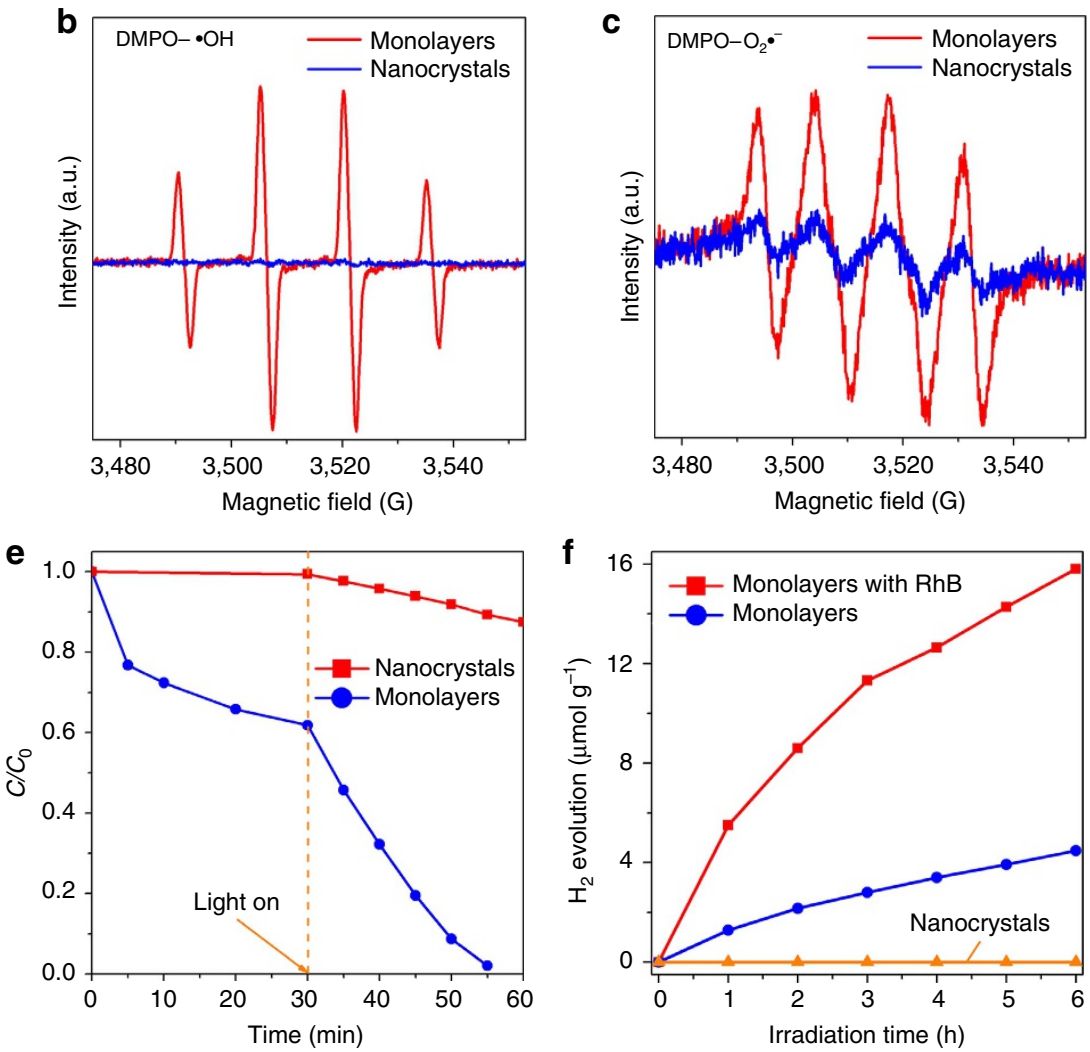

Figure $\mathbf{5}$ | Photocatalytic performances of $\mathbf{B i}_{\mathbf{2}} \mathbf{W} \mathbf{O}_{\mathbf{6}}$ samples. (a) Schematic illustration of photocatalytic mechanism over the monolayer $\mathrm{Bi}_{2} \mathrm{WO}_{6}$. $(\mathbf{b}, \mathbf{c})$ Electron spin resonance signals of $\mathrm{DMPO}-\bullet \mathrm{OH}^{-}$adducts and $\mathrm{DMPO}-\mathrm{O}_{2} \bullet-$ adducts produced by $\mathrm{Bi}_{2} \mathrm{WO}_{6}$ samples under visible light irradiation $(\lambda \geq 420 \mathrm{~nm})$. (d) Photocurrent of $\mathrm{Bi}_{2} \mathrm{WO}_{6}$ samples under visible light illumination. (e) Photodegradation of $\mathrm{RhB}$ over $\mathrm{Bi}_{2} \mathrm{WO}_{6}$ samples $(\lambda \geq 420 \mathrm{~nm}$ ). (f) Visible-light-driven photocatalytic $\mathrm{H}_{2}$ evolution over the nanocrystals, monolayers and RhB sensitized monolayers ( $\lambda \geq 420 \mathrm{~nm}$ ); 0.3 wt $\%$ of Pt was loaded.

sandwich substructure and the Br surface modification lead to decrease of the bandgap and enhancement of the photogenerated charges separation, which are very favourable for photocatalysis.

Open surface of the monolayer $\mathbf{B i}_{2} \mathbf{W O}_{6}$. Different from most reported monolayer materials with closed and inert surfaces ${ }^{21}$, the as-synthesized monolayer $\mathrm{Bi}_{2} \mathrm{WO}_{6}$ possesses oxygen-depleted and highly active surface. Moreover, the $\mathrm{Br}^{-}$ions on surfaces cause the monolayers negatively charged, as proved by the zeta potential in Supplementary Table 1. Therefore, the monolayers can selectively adsorb positively charged species. Figure $4 \mathrm{~b}$ shows the adsorption performances of various organic pollutants over the $\mathrm{Bi}_{2} \mathrm{WO}_{6}$ monolayers. Salicylic acid, as a neutral species, is hardly adsorbed by the monolayers. Methyl orange is positively charged in acid medium (Fig. 4a), and therefore its adsorption is enhanced by changing solution $\mathrm{pH}$ from 7 to 3 using $\mathrm{H}_{2} \mathrm{SO}_{4}$ or $\mathrm{HCl}$. Similar to $\mathrm{Br}^{-}$ions, $\mathrm{Cl}^{-}$could also adsorb at the open metal sites on surface and make the monolayers more negatively charged, as shown in Fig. 4c. Hence, the methyl orange adsorption can be promoted more effectively by $\mathrm{HCl}$ than by $\mathrm{H}_{2} \mathrm{SO}_{4}$. Methylene blue molecules containing both $\mathrm{Cl}^{-}$ions and positive ammonium groups are adsorbed almost entirely. Owing to the open surfaces, the monolayers show much better ability for adsorption of Rhodamine $\mathrm{B}\left(\mathrm{RhB} ; 7.3 \mathrm{mgg}^{-1}\right)$ than the nanocrystals $\left(0.19 \mathrm{mg} \mathrm{g}^{-1}\right)$, though the specific surface area of the monolayers $\left(43 \mathrm{~m}^{2} \mathrm{~g}^{-1}\right)$ is less than twice that of the nanocrystals $\left(28 \mathrm{~m}^{2} \mathrm{~g}^{-1}\right)$. All above results confirm that the surface of monolayer $\mathrm{Bi}_{2} \mathrm{WO}_{6}$ is open and can strongly interact with surrounding species such as water, anions $\mathrm{Cl}^{-}$or $\mathrm{Br}^{-}$and positively charged organics (Fig. 4c).
Photocatalytic performance of the monolayer $\mathrm{Bi}_{2} \mathrm{WO}_{6}$. Since the holes are photogenerated directly on the open surface $[\mathrm{BiO}]^{+}$ layers (Fig. 5a), the monolayers surfaces are highly active for photocatalytic oxidation reactions, such as the oxidation of $\mathrm{OH}^{-}$ to $\cdot \mathrm{OH}$. This feature was verified by the 5,5 -dimethyl-1-pyrroline-N-oxide (DMPO) spin-trapping electron paramagnetic resonance (EPR) technique (Fig. 5b). The $\cdot \mathrm{OH}$ radicals signal is very weak for the nanocrystals under visible light illumination, which is consistent with the previously observation for $\mathrm{Bi}_{2} \mathrm{WO}_{6}$ samples ${ }^{45}$. However, for the monolayer $\mathrm{Bi}_{2} \mathrm{WO}_{6}$, the $\cdot \mathrm{OH}$ radicals signal is much stronger, implying the superior activity of the monolayers for the photocatalytic oxidation reactions. On the other hand, the photoelectrons are formed in the middle layer where they transfer to the edge of monolayers for reduction reactions. Figure $5 c$ shows that the reduction activity of the monolayers for $\mathrm{O}_{2}$ to $\mathrm{O}_{2}^{-}$is enhanced likewise, compared with that of the nanocrystals, although the enhancement is lower for the reduction than for the oxidation. Figure $5 \mathrm{~d}$ is comparison of photocurrents between the monolayers and nanocrystals. It can be seen that the photocurrent from the monolayers is about 10fold higher than that from the nanocrystals. This indicates that the monolayers mimic the heterojunction interface to result in the ultrafast charge transfer and separation. As for the little decrease of photocurrent on the monolayers with irradiation time, this can be because the photogenerated electrons formed in the middle layer need to undergo a long-distance transfer towards the edge, electron accumulation and partial recombination with holes may occur simultaneously with irradiation time.

The photocatalytic performances of $\mathrm{Bi}_{2} \mathrm{WO}_{6}$ samples for photodegradation of $\mathrm{RhB}$ were evaluated under visible light 
illumination $(\lambda \geq 420 \mathrm{~nm})$. As shown in Fig. 5e, the monolayers show much higher visible-light-driven photocatalytic activity than the nanocrystals. Ninety-eight percent of $\mathrm{RhB}$ are degraded using the monolayers as a photocatalyst within $25 \mathrm{~min}$, while only $13 \% \mathrm{RhB}$ are degraded using the nanocrystals within $30 \mathrm{~min}$. Moreover, the monolayers can be efficiently recycled and reused without appreciable loss of activity (Supplementary Figs 17-18). Besides, the monolayers show also an excellent photocatalytic activity for $\mathrm{H}_{2}$ production from water solution under visible light. Figure $5 f$ shows the $\mathrm{H}_{2}$ evolution over the nanocrystals, monolayers and $\mathrm{RhB}$ sensitized monolayers $(\lambda \geq 420 \mathrm{~nm})$ with $0.3 \mathrm{wt} \% \mathrm{Pt}$ loading as a function of time. The $\mathrm{H}_{2}$ evolution activity of $\mathrm{Bi}_{2} \mathrm{WO}_{6}$ has been reported to be very low $\left(1.6 \mu \mathrm{molh}^{-1} \mathrm{~g}^{-1}\right)$ even under a $450 \mathrm{~W}$ high pressure mercury lamp ${ }^{46}$. And the $\mathrm{Bi}_{2} \mathrm{WO}_{6}$ has been considered to have no activity for visible-lightdriven $\mathrm{H}_{2}$ production ${ }^{47}$. As shown in Fig. 5 f, the nanocrystals show indeed no $\mathrm{H}_{2}$ evolution activity, but surprisingly the monolayers exhibit a good $\mathrm{H}_{2}$ evolution activity under visible light. As adding $\mathrm{RhB}$ into the reaction system, ca. fourfold higher activity is observed due to the sensitization effect of RhB. Both the ultrafast charge separation and the highly active surface make the monolayers possess superior performances in solar energy conversion than other nanostructures composed of two or more layers (Supplementary Figs 19-21).

\section{Discussion}

In summary, the freestanding monolayer $\mathrm{Bi}_{2} \mathrm{WO}_{6}$ can be successfully synthesized via a CTAB-assisted self-assembly route. The assynthesized monolayer $\mathrm{Bi}_{2} \mathrm{WO}_{6}$ has a sandwich substructure of $[\mathrm{BiO}]^{+}-\left[\mathrm{WO}_{4}\right]^{2-}-[\mathrm{BiO}]^{+}$. The $\mathrm{Bi}$ atoms in the surface $[\mathrm{BiO}]^{+}$ layers are coordinatively unsaturated and thus the monolayers can adsorb $\mathrm{Br}^{-}$ions to avoid stacking into multilayer. The monolayer $\mathrm{Bi}_{2} \mathrm{WO}_{6}$ shows oxygen-depleted surface, and has a narrower bandgap than the nanocrystals. The sandwich structure simulates the heterojunction interface with space charge to facilitate the ultrafast separation of photogenerated carriers. On irradiation, holes are generated directly on the highly active surfaces, resulting in the excellent activities for the photodegradation of $\mathrm{RhB}$. More interestingly, the monolayering allows $\mathrm{Bi}_{2} \mathrm{WO}_{6}$ to have a visiblelight-driven $\mathrm{H}_{2}$ evolution activity, which can be efficiently enhanced by dye sensitization. This work provides a simple and efficient bottom-up route to prepare novel monolayer materials with ultrafast charge separation and highly active surface.

\section{Methods}

Materials synthesis. In the preparation of $\mathrm{Bi}_{2} \mathrm{WO}_{6}$ monolayers, the start materials $1 \mathrm{mmol} \mathrm{Na} \mathrm{WO}_{4} \cdot 2 \mathrm{H}_{2} \mathrm{O}$, and $2 \mathrm{mmol} \mathrm{Bi}\left(\mathrm{NO}_{3}\right)_{3} \cdot 5 \mathrm{H}_{2} \mathrm{O}$ and $0.05 \mathrm{~g} \mathrm{CTAB}$ were added in $80 \mathrm{ml}$ deionized water. After 30 min stirring, the mixed solution was poured into a $100 \mathrm{ml}$ Teflon-lined autoclave. Then the autoclave was sealed into a stainless steel tank and treated at $120^{\circ} \mathrm{C}$ for $24 \mathrm{~h}$. Finally, the product was collected and washed several times with deionized water and dried at $60^{\circ} \mathrm{C}$ in air for $10 \mathrm{~h}$. In the preparation of monolayer $\mathrm{Bi}_{2} \mathrm{WO}_{6}$ companied with few layers, $0.1 \mathrm{mmol} \mathrm{KBr}$ instead of $\mathrm{CTAB}$ was added in the mixture, while keeping other parameters unchanged. The $\mathrm{Bi}_{2} \mathrm{WO}_{6}$ nanocrystals were prepared without $\mathrm{CTAB}$ and $\mathrm{KBr}$ assistances.

$\mathrm{Bi}_{2} \mathrm{O}_{2} \mathrm{CO}_{3}$ monolayers were prepared by the same route. A total of $2 \mathrm{mmol}$ $\mathrm{Bi}\left(\mathrm{NO}_{3}\right)_{3}$ and $0.05 \mathrm{~g} \mathrm{CTAB}$ were added in $80 \mathrm{ml}$ of $1 \mathrm{M} \mathrm{HNO}_{3}$ solution. After the mixture became a clear solution, $10 \mathrm{mmol} \mathrm{Na}_{2} \mathrm{CO}_{3}$ was added and a white precipitate appeared immediately. This suspension was magnetically stirred for $30 \mathrm{~min}$ to complete the precipitation reaction. Then the suspension was poured into a $100 \mathrm{ml}$ Teflon-lined autoclave and the autoclave was sealed into a stainless steel tank. The sample was treated at $60^{\circ} \mathrm{C}$ for $24 \mathrm{~h}$. Then the reactor was naturally cooled to room temperature. The obtained sample was collected and washed several times with deionized water and dried at $60^{\circ} \mathrm{C}$ in air for $10 \mathrm{~h}$.

Materials characterization. The X-ray diffraction patterns were recorded on a Bruker D8 Advance X-ray diffractometer with Ni filtered $\mathrm{Cu} \mathrm{K} \alpha$ radiation at $40 \mathrm{kV}$ and $40 \mathrm{~mA}$. Ultraviolet-visible diffuse reflectance (ultraviolet-visible diffuse reflectance spectrum) spectra were obtained with a self-supporting sample disk on a ultraviolet-visible spectrophotometer (Cary 500), where $\mathrm{BaSO}_{4}$ was used as a reflectance standard. TEM images were obtained using a JEOL model JEM 2010 EX instrument at an accelerating voltage of $200 \mathrm{kV}$. AFM images were recorded using Agilent 5,500 AFM (Agilent Technologies, USA). All the images were acquired using tapping mode under ambient conditions (ca. $40-50 \%$ relative humidity, $25^{\circ} \mathrm{C}$ temperature). The used Si cantilevers/tips (Bruker) have a spring constant of $40 \mathrm{~N} \mathrm{~m}^{-1}$ and a resonance frequency of $300 \mathrm{kHz}$. During an AFM experiment, sample was dispersed in ethanol using an ultrasonic bath for $20 \mathrm{~min}$ and then the dispersion was diluted in ethanol. A drop of the above diluted dispersion was deposited on a new cleaved mica surface and dried in air. The instrument parameters (set point, amplitude, scan size, scan speed and feedback control) were adjusted for the best resolution of images. Electron spin resonance spectra were obtained over Bruker ESP 300 E electron paramagnetic resonance spectrometer.

Activity evaluation. The photodegradation of dyes were performed in a glass vessel under visible-light irradiation by a $300 \mathrm{~W}$ Xe lamp with a $420 \mathrm{~nm}$ cutoff filter. Twenty milligram of the photocatalyst was added into $80 \mathrm{ml} \mathrm{RhB}$ $\left(10 \mu \mathrm{moll}^{-1}\right)$ solution. The dispersion was stirred in the dark for $30 \mathrm{~min}$ to reach the adsorption equilibrium. Then the visible light was turn on for the photodegradation tests. Three millilitres of the sample solution were taken at given time intervals and separated by centrifugation. The residual concentration of the organics in solution was analysed using a Varian Cary 50 Scan ultraviolet-visible spectrophotometer. The selective adsorption experiments were performed by the same method. The methyl orange (20 p.p.m.), methylene blue (10 p.p.m.) and salicylic acid $\left(500 \mu \mathrm{moll}^{-1}\right)$ solutions were used. $50 \mathrm{mg}$ of the catalyst was used to test the adsorption performances.

The photocatalytic $\mathrm{H}_{2}$ production of samples under visible light irradiation was conducted in a Pyrex reactor connected with a gas-closed circulation system and a vacuum system. In a typical experiment, $20 \mathrm{mg}$ catalyst was dispersed in $100 \mathrm{ml}$ deionized water containing $0.4 \mathrm{~g}$ ethylenediamine tetraacetic acid (EDTA) as a sacrificial reagent. This system was evacuated for $30 \mathrm{~min}$ to remove air prior to irradiation. A $300-\mathrm{W}$ Xe lamp with an optical cutoff filter $(\lambda \geq 420 \mathrm{~nm})$ was used as a light source. The produced hydrogen was quantified by gas chromatography (Shimadzu GC-8A, TCD, Ar carrier). For the RhB sensitization system, RhB $\left(10 \mu \mathrm{moll}^{-1}\right)$ was contained in solution.

Calculation details. First-principles DFT calculations were carried out utilizing the Vienna $a b$ initio simulation package ${ }^{48,49}$. The Perdew-Wang-type (PW91) exchange-correlation functional was employed to study the energies and structures of different $\mathrm{Bi}_{2} \mathrm{WO}_{6}$ systems. Vanderbilt ultrasoft pseudo-potentials were used to describe the interactions between the ion cores and valence electrons for all atoms, and the kinetic cutoff energy was set to $400 \mathrm{eV}$. In the calculations, the convergence energy threshold for self-consistent iteration was set to $10^{-4} \mathrm{eV}$ per atom, along with the residual atomic forces were $<0.03 \mathrm{eV} \AA-1$. For the bulk $\mathrm{Bi}_{2} \mathrm{WO}_{6}$, the optimized lattice constants are $a=5.480 \AA, b=5.468 \AA$ and $c=16.760 \AA$, which agrees well with the experimental values of $a=5.457 \AA, b=5.436 \AA$ and $c=16.427 \AA$. A $(2 \times 2)$ periodic slab model was adopted to simulate different $\mathrm{Bi}_{2} \mathrm{WO}_{6}$ nanosheets, which were constructed from the $\mathrm{Bi}_{2} \mathrm{WO}_{6}(001)$ surface. During the structural optimization, the positions of all atoms and the lengths of two translation vectors of the nanosheet were allowed to relax. The spacing between the adjacent slabs was set about $10 \AA$, and a $(3 \times 3 \times 1)$ Monkhorst-Pack $k$-point mesh was used for integration in the reciprocal space. To investigate the thermodynamic stability of different $\mathrm{Bi}_{2} \mathrm{WO}_{6}$ nanosheets, the surface free energy $(\gamma)$ was calculated, which is defined as following,

$$
\gamma=\frac{E^{\text {slab }}-N E_{\mathrm{Bi}_{2} \mathrm{WO}_{6}}^{\text {bulk }}-N_{\mathrm{Br}} E_{\mathrm{Br}}}{2 A} .
$$

where $E^{\text {slab }}$ is the total energy of the slab, $E_{\mathrm{Bi}_{2} \mathrm{WO}_{6}}^{\text {blk }}$ is the energy of per $\mathrm{Bi}_{2} \mathrm{WO}_{6}$ unit in the bulk, $N$ is the number of $\mathrm{Bi}_{2} \mathrm{WO}_{6}$ unit found in the slab, $N_{\mathrm{Br}}$ is the number of $\mathrm{Br}$ atom, $E_{\mathrm{Br}}$ is the ground state energy of $\mathrm{Br}$ atom, and $A$ is the area of the slab surface.

\section{References}

1. Wang, H. et al. Semiconductor heterojunction photocatalysts: design, construction, and photocatalytic performances. Chem. Soc. Rev. 43, 5234-5244 (2014).

2. Yuan, Y.-P., Ruan, L.-W., Barber, J., Joachim Loo, S. C. \& Xue, C. Hetero-nanostructured suspended photocatalysts for solar-to-fuel conversion. Energy Environ. Sci. 7, 3934-3951 (2014).

3. Marschall, R. Semiconductor composites: strategies for enhancing charge carrier separation to improve photocatalytic activity. Adv. Funct. Mater. 24, 2421-2440 (2014).

4. Li, H., Zhou, Y., Tu, W., Ye, J. \& Zou, Z. State-of-the-art progress in diverse heterostructured photocatalysts toward promoting photocatalytic performance. Adv. Funct. Mater. 25, 998-1013 (2015).

5. Xu, M., Liang, T., Shi, M. \& Chen, H. Graphene-like two-dimensional materials. Chem. Rev. 113, 3766-3798 (2013).

6. Chhowalla, M. et al. The chemistry of two-dimensional layered transition metal dichalcogenide nanosheets. Nat. Chem. 5, 263-275 (2013). 
7. Butler, S. Z. et al. Progress, challenges, and opportunities in two-dimensional materials beyond graphene. ACS Nano 7, 2898-2926 (2013).

8. Geim, A. K. \& Grigorieva, I. V. Van der Waals heterostructures. Nature 499, 419-425 (2013).

9. Wang, H. et al. Two-dimensional heterostructures: fabrication, characterization, and application. Nanoscale 6, 12250-12272 (2014)

10. Duan, X. et al. Lateral epitaxial growth of two-dimensional layered semiconductor heterojunctions. Nat. Nanotechnol. 9, 1024-1030 (2014).

11. Tan, C. et al. Liquid-phase epitaxial growth of two-dimensional semiconductor hetero-nanostructures. Angew. Chem. Int. Ed. 54, 1841-1845 (2015).

12. Gong, Y. et al. Vertical and in-plane heterostructures from $\mathrm{WS}_{2} / \mathrm{MoS}_{2}$ monolayers. Nat. Mater. 13, 1135-1142 (2014).

13. Hong, X. et al. Ultrafast charge transfer in atomically thin $\mathrm{MoS}_{2} / \mathrm{WS}_{2}$ heterostructures. Nat. Nanotechnol. 9, 682-686 (2014).

14. Hou, Y. et al. Layered nanojunctions for hydrogen-evolution catalysis. Angew. Chem. Int. Ed. 52, 3621-3625 (2013).

15. Lin, B. et al. Interstratified nanohybrid assembled by alternating cationic layered double hydroxide nanosheets and anionic layered titanate nanosheets with superior photocatalytic activity. J. Hazard. Mater. 280, 156-163 (2014).

16. Zhang, H., Lv, X., Li, Y., Wang, Y. \& Li, J. P25-graphene composite as a high performance photocatalyst. ACS Nano 4, 380-386 (2010).

17. Huang, Q. et al. Enhanced photocatalytic activity of chemically bonded $\mathrm{TiO}_{2}$ /graphene composites based on the effective interfacial charge transfer through the C-Ti Bond. ACS Catal. 3, 1477-1485 (2013).

18. Sun, Y., Gao, S., Lei, F. \& Xie, Y. Atomically-thin two-dimensional sheets for understanding active sites in catalysis. Chem. Soc. Rev. 44, 623-636 (2015).

19. Guan, M. et al. Vacancy associates promoting solar-driven photocatalytic activity of ultrathin bismuth oxychloride nanosheets. J. Am. Chem. Soc. 135, 10411-10417 (2013).

20. Klein, A. et al. Schottky barriers on layered semiconductors: a comparison between van der Waals and non van der Waals faces. Appl. Surf. Sci. 70-71, 470-474 (1993)

21. Jaramillo, T. F. et al. Identification of active edge sites for electrochemical $\mathrm{H}_{2}$ evolution from $\mathrm{MoS}_{2}$ nanocatalysts. Science 317, 100-102 (2007).

22. Asadi, M. et al. Robust carbon dioxide reduction on molybdenum disulphide edges. Nat. Commun. 5, 4470 (2014).

23. Kibsgaard, J., Chen, Z., Reinecke, B. N. \& Jaramillo, T. F. Engineering the surface structure of $\mathrm{MoS}_{2}$ to preferentially expose active edge sites for electrocatalysis. Nat. Mater. 11, 963-969 (2012).

24. Xie, J. et al. Defect-rich $\mathrm{MoS}_{2}$ ultrathin nanosheets with additional active edge sites for enhanced electrocatalytic hydrogen evolution. Adv. Mater. 25, 5807-5813 (2013)

25. Xie, J. et al. Controllable disorder engineering in oxygen-incorporated $\mathrm{MoS}_{2}$ ultrathin nanosheets for efficient hydrogen evolution. J. Am. Chem. Soc. 135 17881-17888 (2013)

26. Novoselov, K. S. et al. Two-dimensional atomic crystals. Proc. Natl Acad. Sci. USA 102, 10451-10453 (2005).

27. Li, X. et al. Large-area synthesis of high-quality and uniform graphene films on copper foils. Science 324, 1312-1314 (2009).

28. Lee, Y.-H. et al. Synthesis of large-area $\mathrm{MoS}_{2}$ atomic layers with chemical vapor deposition. Adv. Mater. 24, 2320-2325 (2012)

29. Nicolosi, V., Chhowalla, M., Kanatzidis, M. G., Strano, M. S. \& Coleman, J. N. Liquid exfoliation of layered materials. Science 340, 1226419 (2013).

30. Coleman, J. N. et al. Two-dimensional nanosheets produced by liquid exfoliation of layered materials. Science 331, 568-571 (2011).

31. Osada, M. \& Sasaki, T. Exfoliated oxide nanosheets: new solution to nanoelectronics. J. Mater. Chem. 19, 2503-2511 (2009).

32. Sun, Z. et al. Generalized self-assembly of scalable two-dimensional transition metal oxide nanosheets. Nat. Commun. 5, 3813 (2014).

33. Zhang, C. \& Zhu, Y. Synthesis of square $\mathrm{Bi}_{2} \mathrm{WO}_{6}$ nanoplates as high-activity visible-light-driven photocatalysts. Chem. Mater. 17, 3537-3545 (2005).

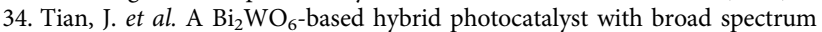
photocatalytic properties under UV, visible, and near-infrared irradiation. Adv. Mater. 25, 5075-5080 (2013).

35. Li, J., Yu, Y. \& Zhang, L. Bismuth oxyhalide nanomaterials: layered structures meet photocatalysis. Nanoscale 6, 8473-8488 (2014).

36. Mann, A. K. P., Steinmiller, E. M. P. \& Skrabalak, S. E. Elucidating the structure-dependent photocatalytic properties of $\mathrm{Bi}_{2} \mathrm{WO}_{6}$ : a synthesis guided investigation. Dalton Trans. 41, 7939-7945 (2012).
37. Feng, Y., Li, L., Li, J., Wang, J. \& Liu, L. Synthesis of mesoporous BiOBr 3D microspheres and their photodecomposition for toluene. J. Hazard. Mater. 192, 538-544 (2011).

38. Huang, H. et al. Ce and F comodification on the crystal structure and enhanced photocatalytic activity of $\mathrm{Bi}_{2} \mathrm{WO}_{6}$ photocatalyst under visible light irradiation. J. Phys. Chem. C 118, 14379-14387 (2014).

39. Li, L. et al. Sub-10 $\mathrm{nm}$ rutile titanium dioxide nanoparticles for efficient visible-light-driven photocatalytic hydrogen production. Nat. Commun. 6, 5881 (2015).

40. Nguyen, S. D., Yeon, J., Kim, S.-H. \& Halasyamani, P. S. $\mathrm{BiO}\left(\mathrm{IO}_{3}\right)$ : a new polar iodate that exhibits an aurivillius-type $\left(\mathrm{Bi}_{2} \mathrm{O}_{2}\right)^{2+}$ layer and a large SHG response. J. Am. Chem. Soc. 133, 12422-12425 (2011).

41. Phelan, W. A. et al. Stacking variants and superconductivity in the Bi-O-S system. J. Am. Chem. Soc. 135, 5372-5374 (2013).

42. Kim, H. G., Hwang, D. W. \& Lee, J. S. An undoped, single-phase oxide photocatalyst working under visible light. J. Am. Chem. Soc. 126, 8912-8913 (2004).

43. Fu, H., Pan, C., Yao, W. \& Zhu, Y. Visible-light-induced degradation of Rhodamine B by nanosized $\mathrm{Bi}_{2} \mathrm{WO}_{6}$. J. Phys. Chem. B 109, 22432-22439 (2005).

44. Yi, Z. et al. An orthophosphate semiconductor with photooxidation properties under visible-light irradiation. Nat. Mater. 9, 559-564 (2010).

45. Sheng, J., Li, X. \& Xu, Y. Generation of $\mathrm{H}_{2} \mathrm{O}_{2}$ and $\mathrm{OH}$ radicals on $\mathrm{Bi}_{2} \mathrm{WO}_{6}$ for phenol degradation under visible light. ACS Catal. 4, 732-737 (2014).

46. Kudo, A. \& Hijii, S. $\mathrm{H}_{2}$ or $\mathrm{O}_{2}$ evolution from aqueous solutions on layered oxide photocatalysts consisting of $\mathrm{Bi}^{3+}$ with $6 \mathrm{~s}^{2}$ configuration and $\mathrm{d}^{0}$ transition metal ions. Chem. Lett. 28, 1103-1104 (1999).

47. Zhang, N., Ciriminna, R., Pagliaro, M. \& Xu, Y.-J. Nanochemistry-derived $\mathrm{Bi}_{2} \mathrm{WO}_{6}$ nanostructures: towards production of sustainable chemicals and fuels induced by visible light. Chem. Soc. Rev. 43, 5276-5287 (2014).

48. Kresse, G. \& Furthmüller, J. Efficient iterative schemes for ab initio total-energy calculations using a plane-wave basis set. Phys. Rev. B 54, 11169-11186 (1996).

49. Kresse, G. \& Hafner, J. Ab initio msolecular dynamics for liquid metals. Phys. Rev. B 47, 558-561 (1993).

\section{Acknowledgements}

This work was financially supported by the National Natural Science Foundation of China (Grant numberss U1305242, 21173044 and 21073035).

\section{Author contributions}

X.X.W. and Y.G.Z. designed the project; Y.G.Z. conducted the most experiments; Y.F.Z carried out the theoretical calculations; M.S.L. performed party of the experiments; J.L.L., Z.Z.Z., and H.X.L. supported the experiments and helped to analyse the results; Y.G.Z X.X.W. together wrote and revised the manuscript with input from all the authors J.C.S.W. took part in the revision of the manuscript.

\section{Additional information}

Supplementary Information accompanies this paper at http://www.nature.com/ naturecommunications

Competing financial interests: The authors declare no competing financial interests.

Reprints and permission information is available online at http://npg.nature.com/ reprintsandpermissions/

How to cite this article: Zhou, Y. et al. Monolayered $\mathrm{Bi}_{2} \mathrm{WO}_{6}$ nanosheets mimicking heterojunction interface with open surfaces for photocatalysis. Nat. Commun. 6:8340 doi: $10.1038 /$ ncomms9340 (2015)

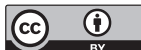

This work is licensed under a Creative Commons Attribution 4.0 International License. The images or other third party material in this article are included in the article's Creative Commons license, unless indicated otherwise in the credit line; if the material is not included under the Creative Commons license, users will need to obtain permission from the license holder to reproduce the material. To view a copy of this license, visit http://creativecommons.org/licenses/by/4.0/ 